\title{
Wood Anatomy of Hawaiian and New Guinean Species of Tetramolopium (Asteraceae): Ecological and Systematic Aspects ${ }^{1}$
}

\author{
Sherwin Carlquist ${ }^{2}$ and Timothy K. Lowrey ${ }^{3}$
}

\begin{abstract}
Qualitative and quantitative features are reported for five Hawaiian and one New Guinean species of Tetramolopium. Tetramolopium bumile differs from the other Hawaiian species in its numerous narrow vessels, numerous vasicentric tracheids, and wide rays. Although these features are adaptive in the dry alpine localities of $T$. bumile, they would be adaptive also in the remaining species, which are from dry to moderately dry lowland localities. Thus, one can consider these features of $T$. humile as systematic indicators. The wood of $T$. pumilum (New Guinea) has distinctive wide, tall rays that may be related to the short stems in this species; T. pumilum has wood more mesomorphic than that of any of the Hawaiian species. Within Hawaiian Tetramolopium, wood anatomy correlates with dryness of habitat. The species of Tetramolopium studied have highly xeromorphic wood in comparison with woods of dicotyledons at large.
\end{abstract}

Tetramolopium, A GENUS of tribe Astereae (Hoffmann 1890), has had a varied taxonomic history (see Lowrey et al. 2001). Cladistic analysis of molecular and morphological data sets (Lowrey et al. 2001) shows that Tetramolopium is polyphyletic. Most of the species are nested within Vittadinia, but $T$. vagans Pedley and, on a different branch, T. pumilum Mattf. are outgroups of Vittadinia. The Hawaiian species of the current study all branch from a single clade. The results of the Lowrey et al. (2001) analysis will lead to taxonomic changes. The inclusion of $T$. pumilum in this study offers comparisons with the wood anatomy of the Hawaiian species. Obviously, study of wood anatomy of the entire "Vittadinia group" of genera is desirable. Because the species composing this group are geographically widespread in Australia and on Pacific islands and are nonwoody, the species have not been studied hitherto except for $T$.

\footnotetext{
${ }^{1}$ Manuscript accepted 17 June 2002.

${ }^{2}$ Santa Barbara Botanic Garden, 1212 Mission Canyon Road, Santa Barbara, California 93105.

${ }^{3}$ Department of Biology, University of New Mexico, Albuquerque, New Mexico 87131.
}

Pacific Science (2003), vol. 57, no. 2:171-179

(C) 2003 by University of Hawai'i Press

All rights reserved bumile (Carlquist 1960, 1994). Some Hawaiian Tetramolopium species are extinct or very restricted in distribution (Lowrey 1986, 1990 ), so the assemblage of material in this study is unlikely to be bettered. The species referred to Tetramolopium are subshrubs. Wood of subshrubs is rarely collected or studied anatomically by botanists. Thus, the availability of the material studied here represents an unusual opportunity to record information on Tetramolopium wood anatomy.

The wood of Tetramolopium is potentially of interest because the genus has speciated on the Hawaiian Islands (11 species, many with infraspecifically distinct populations). Most Hawaiian taxa are restricted to localities that qualify as xeric (Lowrey 1986). These habitats represent a diversity of geological and edaphic formations, ranging from alpine cinders (Haleakalā, Maui) to lithified calcareous dunes (western Moloka'i). Only T. lepidotum occurs in moderately mesic sites, west-facing slopes of ridges in the Wai'anae Mountains, O'ahu (Lowrey 1986). Ecological analysis of wood anatomy of Tetramolopium is appropriate in view of the xeric nature of these sites, because wood anatomy sensitively reflects ecology in Asteraceae (Carlquist 1966). A distinction is attempted here between characters that represent direct adaptation to ecology and those that are systematic indicators regardless of ecology. The study of 
both wild-collected and greenhouse-grown collections of two species gives a credible indicator of the degree of change in quantitative wood features with greater water availability in cultivation. The term "ecological" in this article refers primarily to probable adaptation to degrees of low water availability, but also to several temperature regimes, because some species (e.g., T. bumile) are alpine whereas others are from lowland sites.

\section{MATERIALS AND METHODS}

Voucher specimens for the collections are as follows (collections at UNM unless otherwise indicated): T. arenarium (A. Gray) Hillebr., Lowrey 1639, Saddle Area, 1550 m, Hawai'i; $T$. filiforme Sherff var. polyphyllum (Sherff) Lowrey, Lowrey 1645, 'Ohikilolo Ridge, 915 m, O'ahu; T. humile (A. Gray) Hillebr. subsp. baleakalae, Carlquist H18 (Uc), near summit of Haleakalā, Maui; Lowrey 424, Sliding Sands Trail, Haleakalā, Maui; T. lepidotum (Less.) Sherff subsp. lepidotum, Lowrey 416, NE-facing slope below trail leading to Pu'u Kaua, Wai'anae Mountains, O'ahu; Lowrey 1643, ridge $\mathrm{E}$ of $\mathrm{Pu}^{\prime} u$ Kaua, $850 \mathrm{~m}$, O'ahu; T. pumilum Mattf., Lowrey 1546, 200 $\mathrm{m}$ from saddle separating Guimu and Sindaba River basins in boggy grassland near main trail to Mt. Albert Edward, $2900 \mathrm{~m}$, New Guinea; T. rockii Sherff var. calcisabulorum (St. John) Lowrey, Lowrey 1630, top of small ridge, $30 \mathrm{~m}$, W Moloka'i; Lowrey 435 , on road to Kaiehu Point, Moloka'i. Wood of the Lowrey collections numbered above 1000 was derived from specimens cultivated in the University of New Mexico Biology greenhouses; wood of other collections was collected in the field. Wood samples of only a few specimens collected in the field were of a diameter sufficient to contain mature patterns of wood anatomy. Only a single specimen per collection was available for study.

Small stem size and brittleness of wood texture render Tetramolopium specimens diffcult objects for sectioning on a sliding microtome, although some satisfactory sections were obtained in this way. Slightly more successful results were obtained by rotary microtome sections of softened stems embedded in paraffin, but processed according to the method of Carlquist (1982). Some sections were stained with a safranin-fast green combination and mounted on slides, via xylene, in Canada balsam. Some sliding microtome sections were dried between clean slides, mounted on aluminum stubs, sputter coated, and examined with a scanning electron microscope (SEM). Macerations were prepared with Jeffrey's Fluid and stained with safranin.

Vessel diameter was measured as mean lumen diameter. Vessel grouping was calculated as a mean based on a solitary vessel $=1$, a pair of vessels in contact $=2$, etc. Terms follow the IAWA Committee on Nomenclature (1964), except for the term "vasicentric tracheid," which follows the usage of Metcalfe and Chalk (1950) and Carlquist (2001). The absence of kinds of statistical analysis (e.g., standard deviation, etc.) will be noted by some readers. Such analyses are uncommon in papers on wood anatomy because such limited cell populations are studied and the degree of uniformity of a cell population in wood samples is not great. Data derived from measurements were often derived from a single section. Statistical manipulation of data is simply not justified where the limited number of specimens and portions of specimens studied is so small. However, physiological processes are related to means (e.g., rapidity of wood condition is related to mean diameter of vessels - although even then one does not know for sure what proportion of vessels is functional at any one moment in time). Consequently, the presentation of simple means, a procedure followed in virtually all papers in comparative wood anatomy today, is the procedure followed. One can say that quantitative data in such papers cannot then have statistical significance, but where ecological data, even in crudely defined categories, are offered (Carlquist 1966, Carlquist and Hoekman 1985), the close parallels between simple means and ecological conditions (especially moisture availability) are clear.

\section{RESULTS}

Quantitative features are given in Table 1 with comments in the text that follows here. 
TABLE 1

Wood Features ${ }^{a}$ of Tetramolopium

\begin{tabular}{lcccccrrr}
\hline \hline Species & VG & VD & VM & VL & FL & MH & MW & ME \\
\hline T. arenarium & 3.90 & 10 & 151 & 118 & 345 & 532 & 4.9 & 7.9 \\
T. fliforme & 3.00 & 19 & 299 & 110 & 343 & 1,226 & 4.1 & 3.1 \\
T. bumile-wild & $>10$ & 6 & 641 & 102 & 211 & 991 & 8.4 & 0.9 \\
T. lepidotum & 1.66 & 20 & 124 & 92 & 327 & 411 & 3.0 & 14.8 \\
$\quad$ Wild & 2.89 & 18 & 275 & 91 & 299 & 558 & 4.2 & 6.0 \\
T. pumilum & 1.78 & 20 & 95 & 86 & 280 & 1,502 & 6.7 & 18.1 \\
T. rockii & 6.27 & 11 & 280 & 107 & 305 & 870 & 3.4 & 4.2 \\
$\quad$ Wild & 4.65 & 11 & 469 & 137 & 284 & 1,025 & 3.8 & 3.2 \\
Collections, means & 4.89 & 14 & 292 & 105 & 299 & 899 & 4.3 & 7.3 \\
\hline
\end{tabular}

"VG, mean number of vessels per group; VD, mean vessel lumen diameter, $\mu \mathrm{m}$; VM, mean number of vessels per square millimeter; VL, mean vessel element length, $\mu \mathrm{m} ; \mathrm{FL}$, mean libriform fiber length, $\mu \mathrm{m} ; \mathrm{MH}$, mean height of multiseriate rays, $\mu \mathrm{m} ; \mathrm{MW}$, mean width of multiseriate rays at widest point (number of cells); $M E$, mesomorphy ratio (vessel diameter times vessel element length divided by vessel number per square millimeter). Collections and methods cited in Materials and Methods; voucher specimens not cited as "wild" are from greenhouse-grown collections and have Lowrey collection numbers above 1000.

Qualitative features are reported in the text that follows.

\section{Quantitative Vessel Features}

As seen in transections, vessels in Tetramolopium are mostly grouped in radial multiples. This is most evident in Figures 1 and 4, but may also be seen in Figure 5 (lower half) and Figure 9. The greatest degree of vessel grouping occurs in T. bumile (Table 1, Figures 7,8$)$. Although wider vessels are readily evident in T. bumile wood transections (Figure 7), what appear to be libriform fibers in transection are mostly narrow vessels and vasicentric tracheids, as evident in Figure 8 by the numerous bordered pits (beaded appearance) on the fibriform elements. The range in vessel grouping from 1.78 to $>10$ is greater than in most groups of dicotyledons.

The range in mean lumen diameter in the species studied is from $6 \mu \mathrm{m}$ in T. lepidotum (Figure 4) to $20 \mu \mathrm{m}$ in T. pumilum (Figure 9). However, the narrowest vessels in the genus may be found in T. bumile (Figure 7), both in earlier formed secondary xylem and associated with wider vessels; such vessels are often the same in diameter as libriform fibers. The narrowness of vessels in Tetramolopium is placed in relief by the mean vessel diameter of $99.6 \mu \mathrm{m}$ (outside diameter) reported for di- cotyledons as a whole by Metcalfe and Chalk (1950). The range in vessel density in Tetramolopium is from 95 to 641 vessels per square millimeter, and if one compares vessel density with vessel lumen diameter for the various species, one finds that these two dimensions are close to being inverse.

The range in mean vessel element length in the species studied, $86-118 \mu \mathrm{m}$, is very restricted, almost uniform in comparison with the range in dicotyledons at large. The mean for dicotyledons at large is $649 \mu \mathrm{m}$ (Metcalfe and Chalk 1950). Mean axial diameter of pit cavities in vessels is close to $3.0 \mu \mathrm{m}$, slightly less in some. Vessel wall thickness averages close to $2.2 \mu \mathrm{m}$ in the species studied.

\section{Vessel Morphology}

Perforation plates are exclusively simple. Lateral wall pitting in vessels consists of alternate circular bordered pits; pit apertures are narrowly elliptical. Helical sculpturing is absent on vessel walls. Vessels are less commonly angular as seen in transection (Figure 1), more commonly rounded (Figures $4,5,7$, $9,11)$. Radially widened vessels are present in $T$. arenarium (Figure 1), although they are more nearly circular in outline in the other species (Figures 5, 7, 9, 11). 


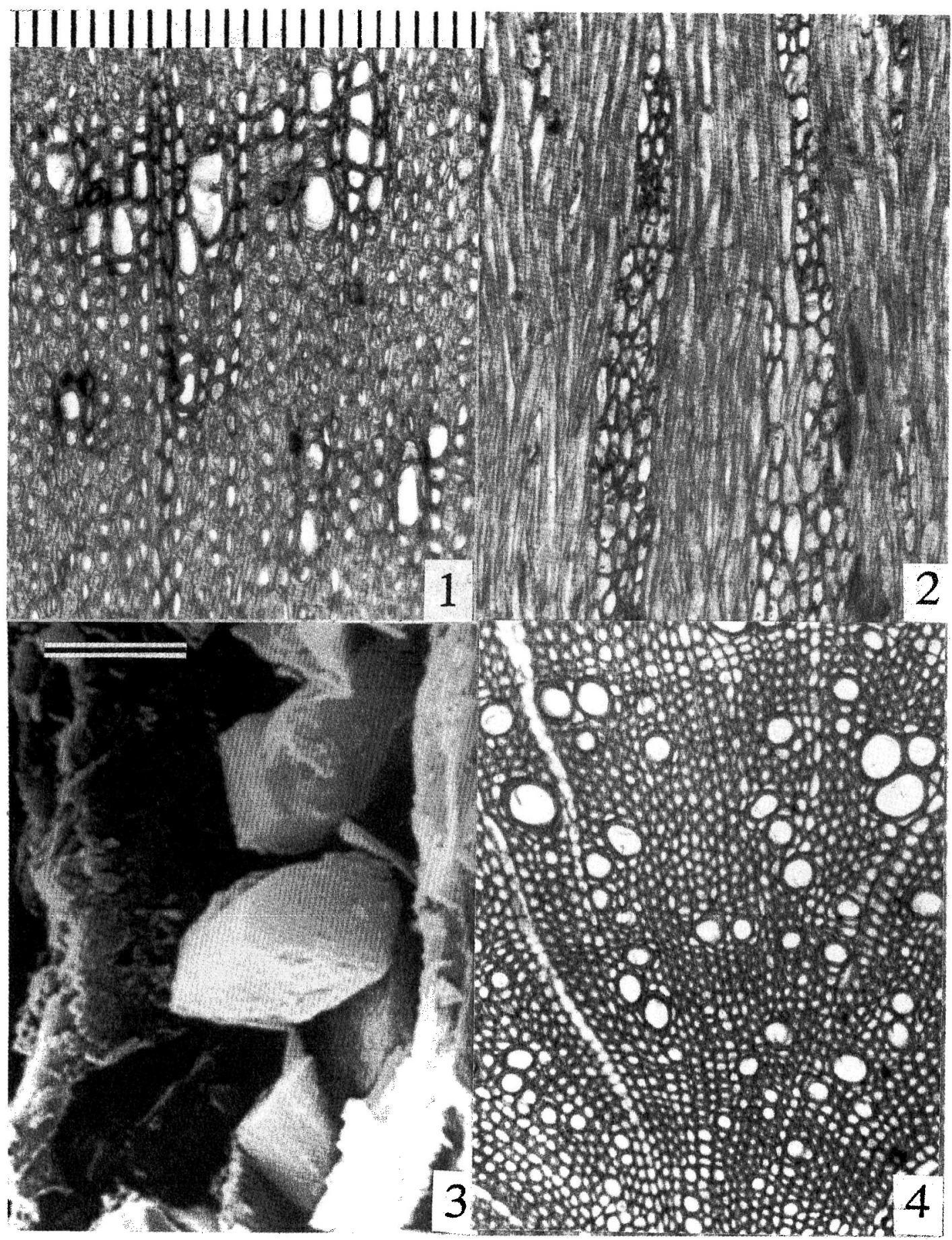

FiguREs 1-4. Wood sections of Tetramolopium. 1-3. T. arenarium. 1, Transection; vessels commonly angular in outline. 2, Tangential section; rays are all multiseriate. 3, Rhomboidal crystals from ray cell of tangential section, SEM photograph. 4. T. lepidotum subsp. lepidotum (Lowrey 416), transection showing vessels narrow in earliest formed wood, wider later. Figures 1, 2, 4, scale in Figure 1 (divisions $=10 \mu \mathrm{m}$ ); Figure 3, scale $=5 \mu \mathrm{m}$. 


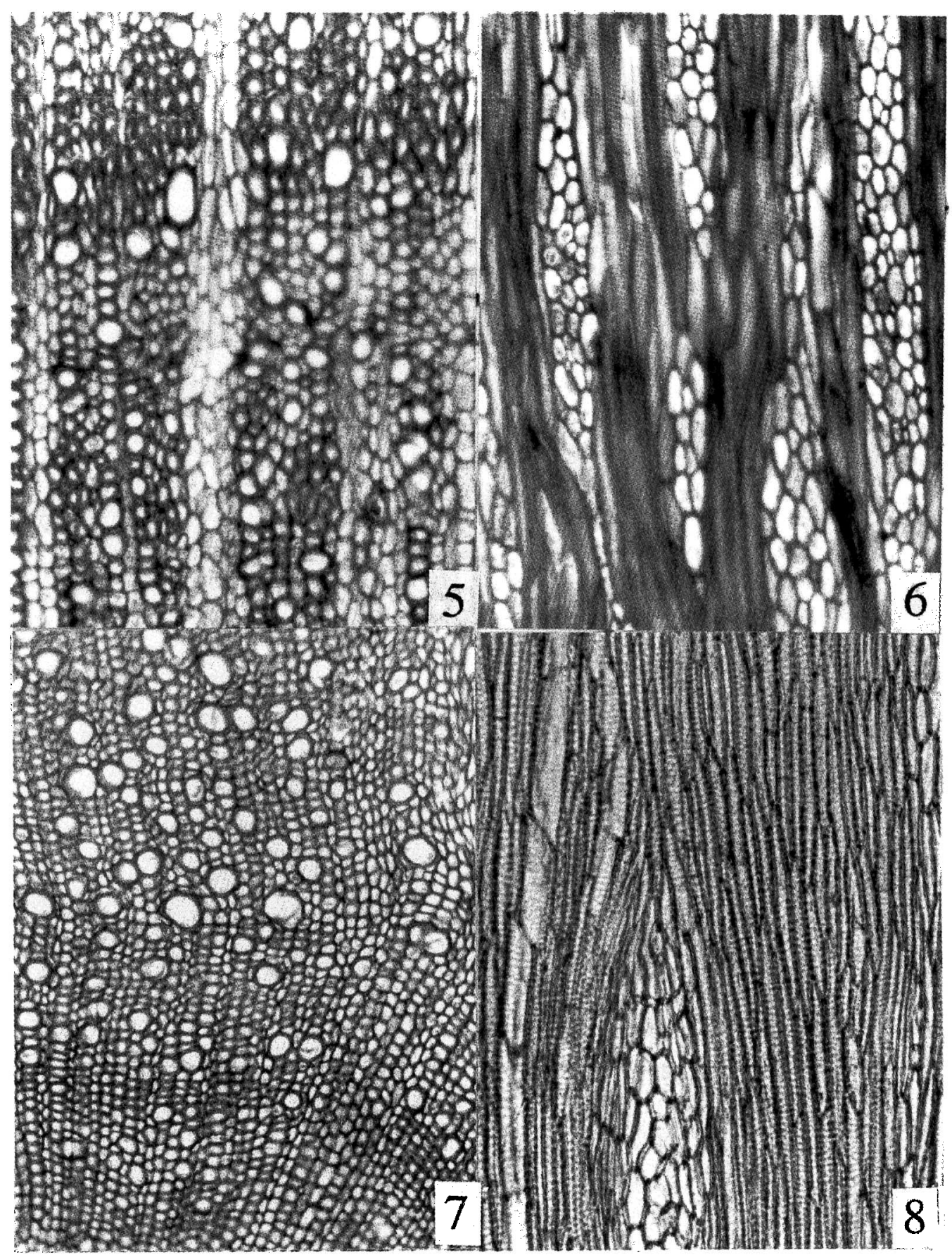

Figures 5-8. Wood sections of Tetramolopium. 5-6. T. filiforme. 5, Transection; large vessels in top half of photograph represent earlywood. 6, Tangential section; rays are tall, narrow. 7-8. T. bumile. 7, Lowrey 424, transection; large vessels near top represent earlywood. 8, Carlquist H15, tangential section; all cells other than vessels (near left) and rays are very narrow vessels and vasicentric tracheids. Figures 5-8, scale in Figure 1. 


\section{Vasicentric Tracbeids}

Vasicentric tracheids were reported earlier in T. bumile (Carlquist 1960, 1994). About half of the elements shown in Figures 7 and 8 are narrow vessel elements, and about half are imperforate and thus must be termed vasicentric tracheids; no libriform fibers are shown in Figures 7 and 8, although small numbers of libriform fibers occur in patches elsewhere in the wood of this species. Vasicentric tracheids were not observed in species other than T. bumile.

\section{Libriform Fibers}

Libriform fibers form the background of wood in the species other than $T$. bumile (compare Figures 6 and 8). Libriform fibers average appreciably longer than vessel elements (the mean ratios in length of the two cell types range from 2.2 to 3.3 for the species studied). Wall thickness of libriform fibers is $0.2-0.4 \mu \mathrm{m}$ greater than wall thickness of vessel elements. Libriform fibers bear minute slitlike pits and are not septate. Radial bands of libriform fibers that are unusually wide tangentially occur in T. pumilum (Figure 9, left).

\section{Axial Parenchyma}

Strands of axial parenchyma consist of a pair of cells with lignified walls in most species. Nonsubdivided axial parenchyma cells with lignified walls were observed in $T$. arenarium and $T$. bumile. Axial parenchyma in all species is vasicentric and scanty; only a few cells are in contact with a vessel or vessel group.

\section{Rays}

Vascular rays consist of multiseriate rays almost exclusively (a very small number of uniseriate rays were observed in $T$. arenarium, $T$. filiforme, and T. rockii). The multiseriate rays average less than five cells in width at the widest point except in $T$. bumile (Figures 7,8 ) and $T$. pumilum (Figure 10). Multiseriate rays exceed $500 \mu \mathrm{m}$ in average height except in $T$. lepidotum (Table 1). Ray cells are predom- inantly upright in $T$. bumile and $T$. pumilum (Figure 10), but in the other species studied, upright, square, and procumbent cells are about equally common (Figures 2, 6, 12). Ray cell walls are about $0.3-0.5 \mu \mathrm{m}$ in thickness and bear small, simple pits. Occasional nonlignified cells were observed in rays of $T$. lepidotum.

\section{Storying; Growth Rings}

No storying was observed in the species other than T. bumile; in that species, vague storying is present (Figure 8). Wider vessels demarcate earlywood in $T$. filiforme (Figure 5, top), $T$. bumile (Figure 7, bottom), and T. rockii (Figure 11 , wide vessels in three bands, at top, center, and bottom).

\section{Cellular Contents}

Rhomboidal crystals were observed in a few ray cells of $T$. arenarium (Figure 3). Darkstaining compounds (yellowish before staining) were observed in vessels or cells adjacent to vessels in $T$. arenarium (Figures 1,2 ), $T$. pumilum (Figure 9), and especially $T$. rockii (Figures 11, 12).

\section{Ecological and Habital Conclusions}

The "Mesomorphy Ratio" (vessel diameter times vessel element length divided by number of vessels per square millimeter) has proved a sensitive indicator of ecology, despite its apparent arbitrary nature (e.g., Carlquist and Hoekman 1985). If this ratio is derived for Tetramolopium species (Table 1), one finds values that are even lower (indicative of more xeromorphy) than those of Californian desert shrubs (Carlquist and Hoekman 1985). The short, narrow vessel elements (numerous per square millimeter) observed in Tetramolopium are features reported to be effective in deterring the formation of embolisms and in restoring water columns after embolisms have occurred (Carlquist 1975, Hargrave et al. 1994, Davis et al. 1999). An additional feature conferring conductive safety is degree of vessel grouping (Carlquist 2001). The more numerous the 


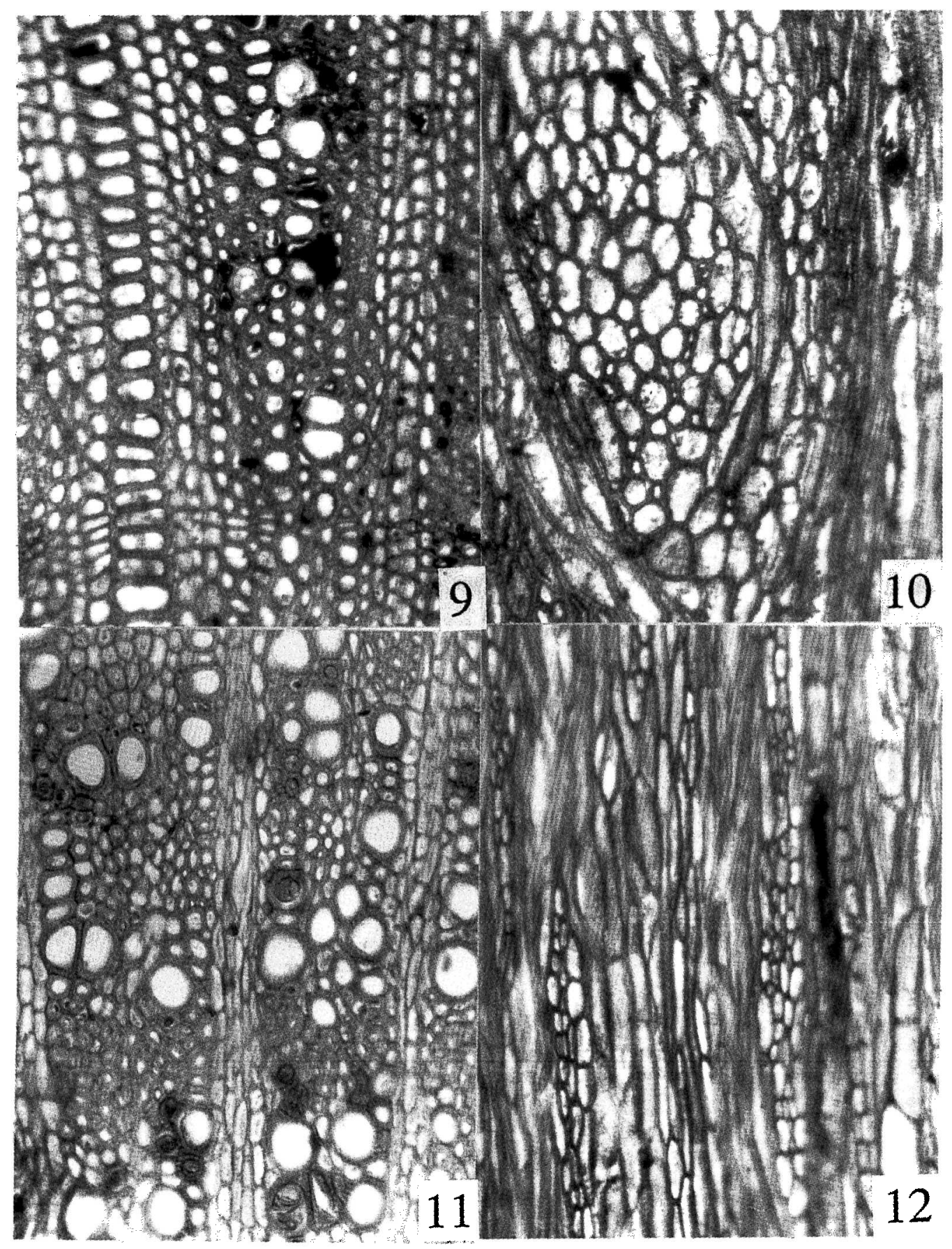

FIgURES 9-12. Wood sections in Tetramolopizm. 9-10. T. pumilum. 9, Transection; radial strip of exceptionally wide libriform fibers near left. 10, Tangential section; notably wide ray shown. 11-12. T. rockii var. calcisabulorum. 11, Transection; dark gray deposits in some vessels and adjacent cells represent oleoresins. 12, Tangential section; most ray cells are upright cells. Figures 9-12, scale in Figure 1. 
vessels in contact within a vessel group, the greater the chances that a conductive pathway can be maintained even if water columns are broken in many of the vessels of the group. The degree of vessel grouping shown in Table 1 is high compared with that of the average species of Asteraceae.

The most xeromorphic of the woods studied here is clearly that of T. bumile, which is the only Hawaiian species that occurs in an alpine habitat where it experiences both drought and freezing. The remainder of the species occur from dry lowland to moderately mesic midelevation localities. Narrow vessels are correlated with drought (Carlquist 1966) and have been hypothesized to resist cavitation under tension (Carlquist 1975). Experimental data supporting the idea that narrow vessels resist drought-induced embolisms better than wide vessels have been provided by Hargrave et al. (1994), and observations suggesting a similar function in freezing-induced embolisms were offered by Davis et al. (1999).

Tetramolopium rockii occurs in such dry sites as the calcareous lithified sand dunes of western Moloka'i (Lowrey 1986), where its narrow, short vessel elements are adaptive. The most mesomorphic wood of the Hawaiian species studied is that of T. lepidotum, which occurs in the most mesomorphic locality of any Hawaiian species, cliff faces of mesic forest, 600-900 m, Wai'anae Mountains, O'ahu (Lowrey 1986). It is interesting that the quantitative wood data parallel the range in habitats from xeric to mesic despite the fact that most of the specimens were derived from greenhouse-cultivated plants (Table 1). However, where a field-collected and a greenhouse-grown wood of a particular species could be compared (Table 1), the field-collected specimen had more xeromorphic quantitative wood features.

The wood of $T$. pumilum, from New Guinea, is slightly more mesomorphic than that of any of the Hawaiian species. The relatively short, thick stems of $T$. pumilum are distinctive and are probably related to the wide, tall rays in this species. The abundance or preponderance of upright cells in Tetramolopium is consonant with the paedomor- phosis hypothesis in wood, which states that rays with a high proportion of upright cells indicate a herbaceous or not strongly woody ancestry for a phylad (see Carlquist 2001).

The increase in vessel diameter with age in a stem (Figure 4) is a feature one often finds in subshrubs or herbaceous perennials, because narrow vessels are conductively safer when roots are mostly in very shallow, readily drying soil, but wider vessels are more adaptive (efficient at rapid conduction) when roots reach deeper soil levels likely to be more steadily moist.

\section{Systematic Conclusions}

The Hawaiian species other than $T$. bumile are thought to be monophyletic based on phylogenetic analyses of morphological and molecular data (Lowrey 1995, Okada et al. 1997, Lowrey et al. 2001). The wood data are consonant with this concept. The storying and the numerous narrow vessels and vasicentric tracheids of $T$. bumile mark it as the most distinctive of the species. Hoffmann (1890) called attention to the nerved achenes of $T$. bumile as distinctive within the genus. Although the wood features of $T$. bumile are adaptive within the genus, they are features that, in other dicotyledonous genera, can be found in lowland species, not just alpine species. Therefore, these wood features may represent autapomorphies of $T$. bumile. Tetramolopium bumile also exhibits several morphological characters that are autapomorphic in the Hawaiian lineage (Lowrey 1995). Phylogenetic analysis of morphology (Lowrey 1995) and RFLP data (Okada et al. 1997) in the Hawaiian taxa suggests that $T$. bumile is an early diverging taxon in the lineage. Furthermore, Lowrey (1995) and Okada et al. (1997) have suggested that evolutionary diversification in the Hawaiian lineage may have resulted from phyletic sorting after a single introduction of a polymorphic species. If true, $T$. bumile apparently possesses wood anatomical and macromorphological features not maintained in the other species in the group that radiated into different habitats.

Rhomboidal crystals in ray cells were observed in the Hawaiian species of Tetramo- 
lopium only in T. arenarium. However, they are not common in material of that species, and the sampling of the Hawaiian species was of necessity incomplete. Therefore, one cannot cite crystal presence as a specific character with certainty. Thoroughness of sampling is a much more difficult problem when materials must be sectioned rather than viewed with a dissecting microscope, and therefore one should cite anatomical features as characteristics of particular species or genera only with reservations.

\section{ACKNOWLEDGMENTS}

The assistance provided by a National Science Foundation Grant (DEB-9200578) to T.K.L. is gratefully acknowledged.

\section{Literature Cited}

Carlquist, S. 1960. Wood anatomy of Astereae (Compositae). Trop. Woods Yale Univ. Sch. For. 113:54-84.

1966. Wood anatomy of Compositae: A summary, with comments on factors controlling evolution. Aliso 6 (2): 1-23.

. 1975. Ecological strategies of xylem evolution. University of California Press, Berkeley. 1982. The use of ethylenediamine in softening hard plant structures for paraffin sectioning. Stain Technol. 57:311-317.

- 1994. Anatomy of tropical alpine plants. Pages 111-128 in P. W. Rundel, A. P. Smith, and F. C. Meinzer, eds. Tropical alpine environments: Plant form and function. Cambridge University Press, Cambridge.

2001. Comparative wood anatomy. 2nd ed. Springer Verlag, Heidelberg.

Carlquist, S., and D. A. Hoekman. 1985. Ecological wood anatomy of the woody southern California flora. IAWA (Int. Assoc. Wood Anat.) Bull., n.s. 6:319-347.

Davis, S. J., S. Sperry, and U. G. Hacke.
1999. The relationship between xylem conduit diameter and cavitation caused by freezing. Am. J. Bot. 86:1367-1372.

Hargrave, K. R., K. L. Kolb, F. W. Ewers, and S. D. Davis. 1994. Conduit diameter and drought-induced embolism in Salvia mellifera Greene (Labiatae). New Phytol. 126:695-705.

Hoffman, O. 1890. Compositae. Pages 88402 in A. Engler and K. Prantl, eds. Die natürlichen Pflanzenfamilien IV(5). Verlag Wilhelm Engelmann, Leipzig.

IAWA Committee on Nomenclature. 1964. Multilingual glossary of terms used in wood anatomy. Verlabuchanstalt Konkordia, Winterthur.

Lowrey, T. K. 1986. A biosystematic revision of Hawaiian Tetramolopium (Compositae: Astereae). Allertonia 4:203-265. 1990. Tetramolopium. Pages 361-369 in W. L. Wagner, D. R. Herbst, and S. H. Sohmer, Manual of the flowering plants of Hawairi. University of Hawai'i Press, Bishop Museum Press, Honolulu. 1995. Phylogeny, adaptive radiation, and biogeography of Hawaiian Tetramolopium (Asteraceae, Astereae). Pages 195220 in W. L. Wagner and V. Funk, eds. Hawaiian biogeography: Evolution on a hot spot archipelago. Smithsonian Institution Press, Washington, D.C.

Lowrey, T. K., C. J. Quinn, R. K. Taylor, R. Chan, R. T. Kimball, and J. C. De Nardi. 2001. Molecular and morphological reassessment of relationships within the Vittadinia group of Astereae (Asteraceae). Am. J. Bot. 88:1279-1289.

Metcalfe, C. R., and L. Chalk. 1950. Anatomy of the dicotyledons. Clarendon Press, Oxford.

Okada, M., R. Whitkus, and T. K. Lowrey. 1997. Genetics of adaptive radiation in Hawaiian and Cook Islands species of Tetramolopium (Asteraceae: Astereae). I. Nuclear RFLP marker diversity. Am. J. Bot. $84: 1236-1246$. 